\title{
Dimensions of Heritage and Memory
}

Multiple Europes and the Politics of Crisis

\section{Edited by Christopher Whitehead, Susannah Eckersley, Mads Daugbjerg and Gönül Bozoğlu}

First published 2019

ISBN: 978-1-138-58946-9 (hbk)

ISBN: 978-1-138-58947-6 (ebk)

\section{Dimensions of European heritage and memory ${ }^{1}$}

A framework introduction

Christopher Whitehead, Mads Daugbjerg, Susannah Eckersley and Gönül Bozoğlu

(CC BY-NC-ND 4.0)

\section{Routledge





\title{
1 Dimensions of European heritage and memory ${ }^{1}$
}

\author{
A framework introduction
}

\author{
Christopher Whitehead, Mads Daugbjerg, \\ Susannah Eckersley and Gönül Bozoğlu
}

\section{Critical framings}

This book is a reflection on the politics of heritage in Europe at the present time, in a moment of pluralised conceptions of the political, social and demographic organisation proper to Europe. It is not a book that seeks to survey, define or characterise an enduring 'European heritage' as an entity, but rather to explore what heritage does - how it is understood, instrumentalised and what it enables - within what we will argue is a 'critical' moment for both identities and geopolitics in Europe.

All of the research that we present in this volume was articulated in relation to a project - entitled Critical Heritages of Europe, or 'CoHERE' - that received European Union (EU) Horizon 2020 research and innovation funding between 2016 and 2019. ${ }^{2}$ CoHERE examined how identities in Europe are articulated in representations and performances of the past - whether at the level of policy, in heritage festivals and sites, school curricula, museums and memory practices or in party politics. The project involved multiple institutions (including museums) across Europe and Turkey. It represented one of the most pluridisciplinary platforms to date for understanding the past in the European present in all of its forms and complexity. The project viewed heritage in Europe as malleable matter through which actors make different realities and imprint different desires, whether for a pan-European sense of community and belonging, or a nostalgic return to simpler times as a defence against change and threat. This book is just one result of that project, although it is a keystone for the larger edifice. It is a team effort, hence its somewhat hybrid character as something between a monograph and an edited collection. It is also a hybrid in other ways: part multidisciplinary cultural study, part collective travelogue, this book combines heritage scholarship of different kinds - critical, poetic, analytical, creative, political and even cinematographic - to do some wayfinding in European place, time and society. Although different contributors have had different levels and types of involvement, all share a critical orientation towards the cultural significance of the past for contemporary geo- and identity politics in and of Europe.

Our project responded to a key policy concern of the 2010s, which located 'cultural heritage and values... at the heart of our capability of overcoming the 


\section{Christopher Whitehead et al.}

current EU crisis'. In a moment of popular disaffection, an EU policy drive sought to provide 'a solid basis for the emergence of a truly European cultural heritage' as a positive counter to the negative effects of crisis, a means of collectivisation based on shared histories. This was a way of fostering a supranational demos constituted not through effective political representation (in fact, voter turnout at European elections has been both low and in decline since 19793), but through its own self-identification as a cultural and historical community, a process sometimes termed 'reflexive Europeanisation'. Heritage, in this view, is understood to play 'a key role in providing a sense of European belonging and EU citizenship as distinct from, but combined with, national citizenship'. ${ }^{4}$

One of the reasons for this book, and the research project that produced it, is that a conglomeration of crises has come into view over the last decade or so, the combined effect of which is an increasingly bitter contest over identities, ways of life and us/them relations. Within this crisis formation are, interconnectedly: disaffection resulting from the 2008 financial crash, from de-industrialisation and austerity; the frequently-remarked rise of nationalisms, including the open return of Fascist or quasi-Fascist ideologies; the stresses - practical and moral of coping with mass refugeeism, particularly from Africa and the Middle East; the 'failure' of multiculturalism remarked by important political figures such as Angela Merkel and David Cameron; the threat of a fragmentation of the EU (constituting, in the eyes of some, the first signs of its wholesale disaggregation); and a loss of faith in the union as a political and social project. A 'critical' moment can be one in which the turning point is in view: things can succeed or fail from now on; the patient (in a 'critical condition') can live or die; it is a perceived degeneration from stability. Crisis is also a condition in which social actors look around themselves and are sometimes upset and critical (Eder, 2014, p. 221), seeking to 'make sense of things', and sometimes desiring change or seeking to revert in some way to previous situations and orders. What does heritage do, and what are its dimensions, in such a moment?

To be clear, we take this configuration of crises as a set of interlinked structural and discursive phenomena. Crisis, as Reinhardt Koselleck (2006) indicated, is a Schlagwort, a catchword. It has the capacity to accommodate and express multiple senses that things have gone wrong. It has its temporal logic, meaning that there was a time before crisis, there was a sliding-into crisis and there is an envisaged aftermath too. It says, 'we are in the thick of a difficult time'. But so many facets of experience, as well as many different phenomena, can be contained in the word that its actual meaning can be ambiguous, in a way that makes for a generalised sense of malaise rather than detailed understandings of complexity. The temporal order of what led to what, and what is a cause and what a symptom, often traduces the intersecting, dynamic, relational and intertextual nature of problems. What is the crisis and wherein? Journalist Natalie Nougayrède (2016) shows how this can be flipped in her correction: 'Europe isn't confronted with a refugee and migrant crisis. It's the refugees and migrants who are confronted with a crisis of Europe. ${ }^{15}$ This is not just wordplay. Such discursive disagreements about explanations, causalities, causes and instigators of 
crisis - as in the frequent debates over where to lay the blame: immigration or austerity; EU policy or bankers' greed? - turn into significant social cleavages with very real consequences, for example through referenda.

The word crisis effects itself, and there is sometimes no clear bar between signifier and signified. It may refer to structural conditions of disadvantage and would likely have little purchase without such reference, but it is also capable of grossly simplifying causes and conditions and amplifying affects. An increased sense of crisis, a general prevalence of the concept of crisis as an explanation for contemporary ills has the potential, in turn, to foster actions that effectively exacerbate those ills. This is comparable to what Thomas Hylland Eriksen calls an 'overheating' of crises, which are themselves produced through the acceleration of globalisation and the ensuing clashes between global and local scales, between the 'system-world' and the lifeworld.

[the] globally interconnected world may be described through its tendency to generate chronic crises, being complex in such a way as to be ungovernable, volatile and replete with unintended consequences - there are double binds, there is an uneven pace of change, and an unstable relationship between universalising and localising processes.

(Eriksen, 2016, p. 7)

It is here, within the tense grounds of negotiating crisis at semantic, practical and political levels, that heritage takes on additional roles in the European present as both cause and cure, as this book will explore.

As mentioned, a core preoccupation of European-level ${ }^{6}$ instrumental uses of heritage has been to provide a positive identity narrative rooted in a rich and varied, and yet shared, European past. This has been part of a shift in understanding at policy levels that heritage can be an important driver of economic prosperity relating to cultural tourism, urban or rural regeneration and connections to the creative industry. Moreover, the idea of a shared heritage has been mobilised to counteract disaffection with the social and political project of the EU and to provide people with a sense of collectivity and belonging. 'Cultural heritage is now widely appreciated as an essential part of Europe's underlying socio-economic, cultural and natural capital,' as proposed in a recent EU report entitled Getting Cultural Heritage to Work for Europe (EU Directorate-General for Research and Innovation, 2015, p. 5). In this view, heritage promises to offer a way out of crisis.

However, while key EU heritage representations (e.g. the Parlamentarium and the House of European History opened in Brussels in 2011 and 2017, respectively) may present coherent images of a historically-founded, shared European identity, the actual social purchase of this can be weak, since diverse actors understand both 'crisis' and 'heritage' differently, and sometimes in ways not framed by a sense of European collectivity but by reference to national, ethnic or other communities instead. That is, they have different conceptions of what the crisis is, where it comes from, who is to blame and what can cure it. 
There are multiple historical backstories at play, and heritage claims are frequently at work in proposing alternative ways out of crisis, whether as reflexive Europeanisation or a reversion to a mythic national past when life was supposedly harder but better. At the 'cognitive scale' of day-to-day lives - 'the size of your perceived world' (Eriksen, 2016, p. 29) - people are unequally able to accommodate change, and a process of alienation from large-scale, authoritative systems of identity-making compels some to seek alternative orders as an antidote to the present. Certain pasts become reservoirs of symbols whose 'necessary ambiguity' (Guibernau, 2013, p. 97) permits people to make meanings and mobilise them creatively and sometimes tactically. Consider, for example, the frequent reliance of 'Leave' activists in the UK Brexit referendum campaign on the medieval Magna Carta charter of rights to defend British 'sovereignty' against the perceived domineering and controlling designs of the EU.7 The alternate heritages and the frictions between them as they move within, and configure, social and political realities, are both effects and causes of crisis. Investigating these dissonances is part of this book.

Over the course of this introductory chapter, we examine the notion and effects of the idea of European heritage; we set out some of the key frameworks that the book as a whole will adopt; we consider the significance of heritage in times of crisis, and we introduce the different chapters. What does heritage do, in a situation of crisis, for identities, for geopolitics, for reflexivity, for good? We will return to these themes and assumptions repeatedly, and to the instrumentalist agendas that sit below them. To begin to pick away at them, let us contrast two invocations of European heritage that fell within the timescale of our research:

The aim of the European Year of Cultural Heritage is to encourage more people to discover and engage with Europe's cultural heritage, and to reinforce a sense of belonging to a common European space... Cultural heritage shapes our identities and everyday lives. It surrounds us in Europe's towns and cities, natural landscapes and archaeological sites. It is not only found in literature, art and objects, but also in the crafts we learn from our ancestors, the stories we tell to our children, the food we enjoy in company and the films we watch and recognise ourselves in... You may think of heritage as being 'from the past' or static, but it actually evolves though our engagement with it. What is more, our heritage has a big role to play in building the future of Europe. ${ }^{8}$

(European Union, 2018)

Everyone can see that Europe is reeling from an unprecedented wave of mass migration. The policy [of accommodating non-European refugees in EU member states] which Brussels is now pursuing will lead to civilisational disaster. The nature of civilisational disaster is that it does not happen overnight. Instead it proceeds slowly, but inexorably, as differences in fertility rates and repeated flows of mass migration change the composition and 
culture of the European population. One tends to take one's eyes off the historical and civilisational horizon, as there are enough problems in the here and now, in our everyday lives. Everyday life will continuously adjust, conform, and accept. This is in its nature. And in the end one will be unable to recognise one's own world... We may lose our European values, our very identity, by degrees like the live frog allowing itself to be slowly cooked to death in a pan of water. ${ }^{9}$

(Viktor Orbán, 2016)

We hope the reader will agree that there is quite a different feel to these two statements, although both of them refer, in one way or another, to the idea of a shared European heritage. In other ways the quotations represent quite different agendas, and they were produced in different contexts. One is a top-down European-level $^{10}$ initiative to encourage participation in the 2018 'European Year of Cultural Heritage' (EYCH), either as audiences or as organisations which, by staging congruent events, could obtain use of the $\mathrm{EYCH}$ visual identity and a calendar listing on the official website. The other is the wording of the Hungarian premier, Viktor Orbán, speaking in the Hungarian Parliament during the height of what has become known as the 'Refugee Crisis'. Both excerpts make use of the possessive pronoun 'our', but in radically different appeals. Orbán is exhorting his national electorate to vote 'no' in his country's 2 October 2016 referendum, to the question: 'Do you want the European Union to be entitled to prescribe the mandatory settlement of non-Hungarian citizens in Hungary without the consent of parliament?' Although their moods are different, both are exhortations to feel attachment, to identify, and to collectivise, in relation to the referent of a 'European' past.

In the EYCH statement, heritage is seen as a legacy to be both shared and transfigured, something that binds together all those who find themselves in 'European space' (a somewhat vague term, to which we will return), regardless of difference, in a politics of civility and mutual recognition of one another's rightful belonging. Here, European heritage is an implicitly positive quantity, aligning with a policy position that 'European heritage' could be called on to create a 'more positive narrative for people' suffering from the consequences of a number of intersecting exonomic, social and political crises (Krasnai, 2017).

In Orbán's rhetoric, 'heritage' is not referred to directly, although he is keenly interested in it. ${ }^{11}$ But it is implied in the ideas of 'European values' and singular 'identity' that have somehow built up over time, that are - theoretically - a legacy of a way of life, a mindset, a common frame of experience: as he puts it, 'one's own world', which has its 'historical and civilizational horizon'. In this world-view, these horizons, values and this identity are under threat from others - especially, as a reading of the full speech will disclose - Muslims. It follows that not everyone can or should be allowed to have a 'European' identity, and this is made yet more explicit later on. For Orbán, the historical identity that the Hungarian electorate shares is what militates against the admission of difference, against the possibility that others might belong. 
We present these two statements as a kind of split-screen of contrasting images of Europe through more or less implicit references to its past and future. They model particular affective 'scripts' that actors - whether organisations or members of an electorate - are encouraged to follow in framing identities: celebration, inclusivity and intercultural recognition in $\mathrm{EYCH}$, versus othering, resentment and the need to defend 'one's own world' in Orbán's speech. Such scripts mobilise ideas of heritage to encourage the cultivation of a particular 'self-in-history'. This term refers to how we understand ourselves as members of a historical trajectory running up to the present and into the future: how we position ourselves in chronologies and narratives; what historical symbols we use to orient our moral compasses; with whom we group ourselves, over variable spans of historical time, such that we might claim ethnic, cultural, moral or spiritual descendance from populations and cultural groups who lived decades, centuries or millenia ago. A self-in-history is our sense of how history has made us who we are, or who we should be.

We would argue that the 'Europes' in the EYCH and in Orbán's speech, and in the scripts that they suggest, are produced in entirely different dimensions - a key term to which we return below - where different techniques, strategies and tactics are possible. The EYCH offered an organisational frame for disparate activities, but it regulated the content of that activity through qualifying criteria. It allocated status, helped organisations to generate publicity and bestowed cultural capital and authority upon them. Orbán, on the other hand, used the techniques and tactics available to him in the different dimension of state and party politics: subtly inflecting the terms of the referendum question to influence people's emotional responses; making a publicised speech in parliament, replete with rhetorical devices such as the boiling frog, to appeal to audiences and frighten them; giving exclusive interviews to pro-government media, scheduled to heighten the speech's impact; and so on. We can debate the real-life consequences of the EYCH's call for identity building across 'European space' or of Orbán's speech for Hungarian state policy (in fact, although an overwhelming majority of voters did follow Orbán's bidding, the referendum was invalidated due to insufficient turnout). But none of this is just imagination, or just discourse. Somehow, through some effects, different 'Europes' are called into being through these kind of 'dimensional' acts. And these Europes are not the same. In fact, their co-existence is a tense one.

\section{Is there a European heritage?}

This game - of contrasting two different expressions of what is supposed to be one thing - leads us to an unavoidable existential question: is there a European heritage?

This is an existential question as much as it is a political one, because heritage is so frequently the grounds for claims relating to an ontological reality in the present. The ontological claim is to say that 'Europe' is something more and other than mere discourse, semantics, politics, contingency and convenience. If 


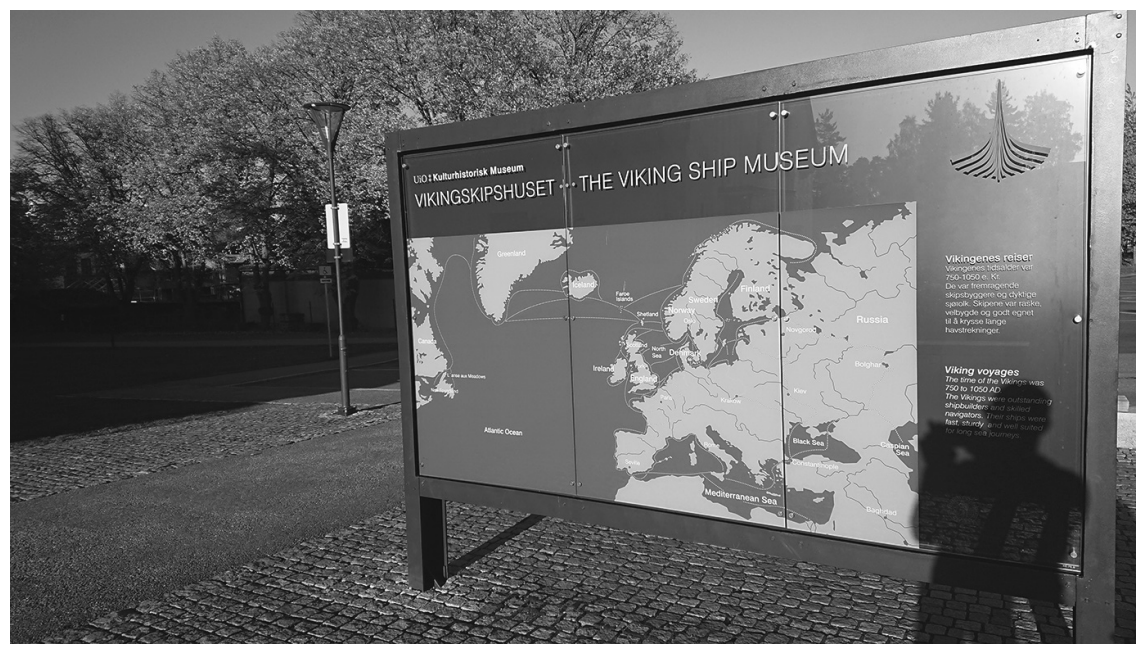

Figure 1.1 A map of the Viking world at the Viking Ship Museum in Oslo, opening a window onto historic global formations and crossings overlaid onto the familiar cartography of today.

we take Europe to exist as something real, and not just as a chimerical idea, then it must have a past that we recognise as having structured the shape of the present; a past that has made this something expressly, unequivocally and exclusively 'European'.

Attempts to identify, classify and catalogue what Europe is - less in terms of geography (which is hard enough) and more in terms of the pasts that matter, cultural distinctiveness and the values that people derive from them - have been features of recent scholarly literature (e.g. Pomian, 2009; Leggewie, 2010; Macdonald, 2013; Delanty, 2018) as well as political and policy discourse such as the Council of Europe's Conclusions on Cultural Heritage as a Strategic Resource for a Sustainable Europe (2014) $)^{12}$ and the aforementioned Getting Cultural Heritage to Work for Europe report (EU Directorate-General for Research and Innovation, 2015). As we will see, such attempts are more or less nuanced and more or less strident. Therein, a core problem is the inevitable tension between claims for distinctiveness and the need to be inclusive and alleviate differences. This tension is evident in both of our contrasting quotations above, as well as in the Council of Europe and European Union refrain of 'Unity in Diversity'. A further problem is what is taken for granted - what features, stories and characteristics are understood as givens - in the rhetorical conviction that Europe exists as a long-standing and unique cultural formation.

Against such a conviction is the possibility of existential negation of a kind associated with 'strong' or 'hard' social constructionism, proponents of which might suggest that 'Europe' has no particular ontology and is nothing more than 
a mass of changeable ideas circulating across changeable lands and seas. This is far from our view. Of course, when we switch to a millennial timescale, we face the fact that there was a time when there was no 'Europe', and that there will be again; or that its physical shape as a landmass has changed markedly. In that sense, Europe is a historical 'construction'. But to stick to the present, we can speculate as to whether a fear of the void of meaning is one of the drivers of an ontological-historical project that calls upon heritage to claim that Europe is, 'merely' because Europe was and has been.

It is relatively common and accepted to debunk essentialising views of Europe (see, for example, Guibernau, 2007, pp. 89-98), although this is not universal practice. But to conceive of a Europe devoid of particular particularity devoid, in a sense, of a self - may be more upsetting, much as it can be to contemplate the inexistence of the human soul. Heritage - understood as the idea of a past, howsoever manifest, narrated and embodied, that matters in the present - can be seen and called upon as a precondition of genuine existence and a guarantee of political legitimacy. To be able to document 'having a culture', to recall an earlier expression from Richard Handler (1985), has become crucial in many contexts today. That is why heritage has such core political salience. The issue can be expressed as circular logic. For there to be a European heritage, there must be such a thing as Europe. For Europe to be, it must 'have' a heritage.

At the time of writing, the formation, coherence and legitimacy of a European polity are subject to exceptional critique and strain, and the political stakes are immense. This explains how critical a general confidence in the existence of a 'European heritage' is, and how important it is for actors across all sorts of societal settings to control, and to invest or disinvest in, its meanings. Europe exists as a geopolitical formation upon its identification as such, which requires historical imaginations of its making, which is to say, a backstory. The meaning of Europe is inextricably connected to the issue of how it has come to be. Historical literature and museum displays and exhibitions duly track this back to different origin stories (Lähdesmäki, 2018). But the stories are multiple, and the contests over what Europe is are incessant. Its shape and cultures have changed dramatically, and will again. In this sense, the attempts to define European heritage that we observe in museums, in historiography, in policy, in heritage lists and sites, are parts of a somewhat anxious project of fixing in place something inherently mutable and transitory.

Our response to European-level assumptions and desires concerning the collectivising and civilising power of heritage is to complicate them. We show that while heritage may indeed have such potentials, it is also a point of contention. Therefore, it is an inherently plural and contradictory object, amenable to instrumental use by actors interested in promoting xenophobic attitudes to the European past, present and future. While heritage is often seen as a means to address social antagonisms and disadvantages, it is also embedded within them and can be part of the range of symbolic and affective means and attachments through which divisions are created, maintained and exacerbated.

'Europe' is an unhelpful term in other senses. Although it is not to be conflated with the European Union (which grows and can shrink) or the Council of 
Europe, often the heritage policy that emerges from these entities has application wider than their membership. As we saw in the EYCH rhetoric at the beginning of this chapter, in some cases the term 'European space' is preferred. Is this space understood geologically or geographically - dimensions of which few people have precise knowledge? Does it refer to the totality of EU member states? (In fact, candidate and non-EU countries such as Turkey, Iceland and Armenia participated in the EYCH project). Or could 'European space' be taken to include places where European presence has had a lasting effect, such as colonies and settlements? This last interpretation would leave the idea of European space phenomenally open, were it not for a tacit and seemingly general desire to contain it and set up boundaries. This is lest 'Europe' overspill and require recognition the world over This would surely have troubling consequences for celebratory heritage discourse relating to Europeanness and European achievement, once histories of colonialism, appropriation by force and suppression of peoples were to be recognised (see Chapter 8, this volume).

\section{Box 1.1}

In undertaking research for this book and other publications, we conducted short visitor questionnaire surveys at a number of heritage sites and museums in various countries within Europe, predominantly within European Union member states. The questions we asked changed to respond to the nature of the setting, but we always asked questions about identities. In non-hierarchical order, we made a series of suggestions of identity categories and asked people to number these in order of importance to themselves. Our suggestions included some perennials: national, regional, European, as well as non-place-based categories: religion, sexuality, gender, alongside a number of blank spaces for people to fill in as they wished. This was intended to avoid closing down possibilities, even though the questionnaire delivery was intended to be rapid. Very often, as people went through the identity options on offer (or found them inadequate) they said interesting things about their choices and deliberations.

In one site in the UK, one of the current authors surveyed a British woman in her late $50 \mathrm{~s}$, on a day out with her family to a heritage event. When she came across the check box for 'European', she rejected it matter-of-factly: 'I'm not European', she said, 'so I can't put anything there.' Neither she nor her known ancestors had immigrated to the British Isles and she considered herself native to them. The interview took place some 18 months after the Brexit referendum of June 2016, and indeed the respondent later stated that she had voted for the UK to leave the EU. Yet her refusal of European identity was not quite a matter of reactionary politics. As she explained, she did not disdain Europe; it was simply because the British Isles were not part of Europe, as if they were themselves a continent.

At one level - that of official and established knowledge - she was quite wrong: the British Isles are, in such a view, an archipelago on the same tectonic plate as 'continental Europe', with a long history of connection and cultural sharing. But at another, her response illuminates precisely the contingencies and arbitrations of human orderings of the world. 
Lastly, 'Europe' and 'European' are floating signifiers that are hitched to very different understandings and political desires. We see this in our game of contrasts between the expressions of EYCH and Viktor Orbán, but the idea of Europe is certainly also sometimes attached to extremely uncivil political ideologies and racisms, not just in Europe itself but also in North America and elsewhere. This adds to the difficulty in pinning down 'Europe' and fixing its contents - physical, intangible, axiological - into place. We can surely find Europe outside of geographical Europe, in the church spires of Lucknow (Lakhnau) or in the 'Danish' village of Solvang in California. A web search shows up a further appropriation of 'European heritage', for this is, at the time of writing, the name of a company that sells luxury kitchen and bathroom tiles. Here we see the connotational and consumerist value of the term, as one capable of bestowing symbolic capital that sells because of Europe's distinguished past, cultural prestige and canonicity.

We elect, in this book, not to untangle this knot of meanings to propose a certain Europe, but rather to examine it in its multiple discursive iterations, as it appears in different settings through different contingencies, techniques and politics. Europe's 'coverage' remains mutable and its meanings contestable and

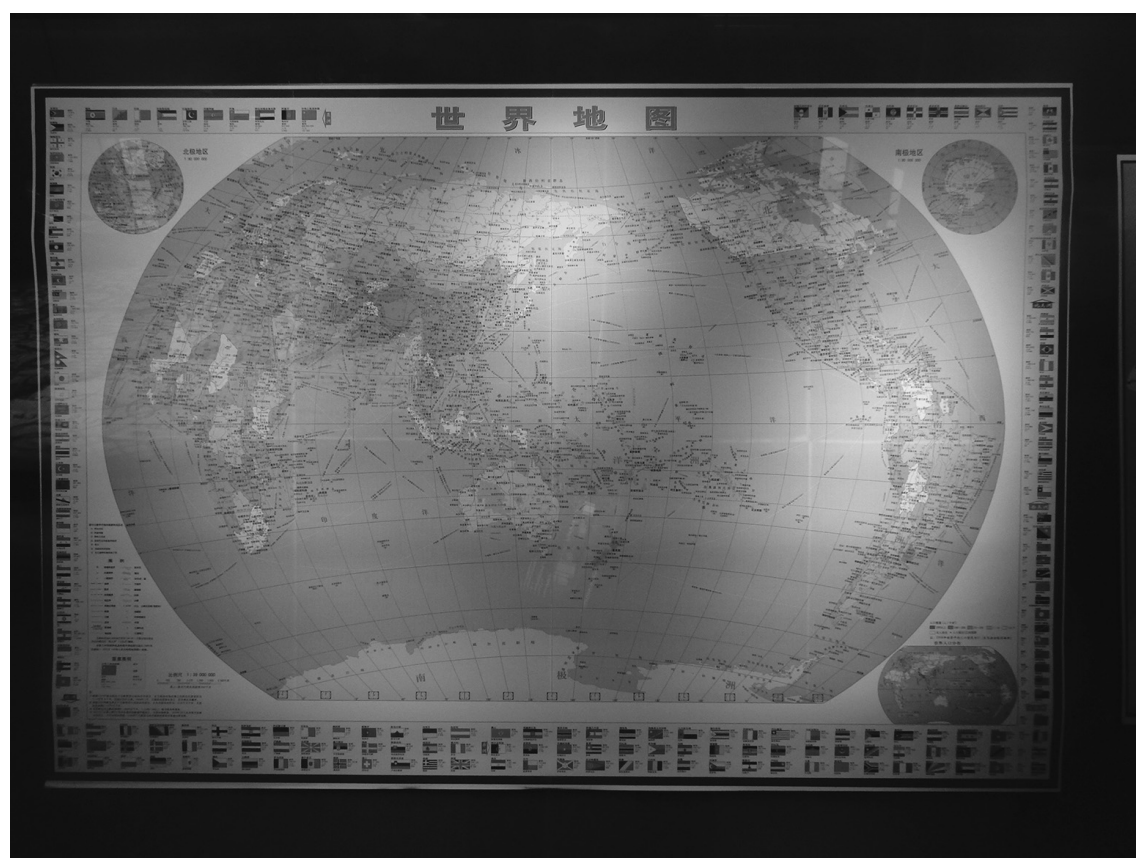

Figure 1.2 At the House of European History in Brussels many of the visitors whom we interviewed were struck by this Chinese map of the world, in which Europe is decentred and placed on the (left-hand) edge. The map is one of the first objects to be encountered, setting up questions about Europe's place in the world and challenging conventional perspectives. 
hard to distinguish, which is, as we will see, both an opportunity and a problem. As a malleable matter, Europe can be and is configured instrumentally for political interests, in various contradictory ways. As an indistinct, rhetorical form, we will see later in this book that it can be unconvincing for some as a vehicle for collectivism, leading to popular deficits of identification, solidarity and faith in the idea of a supranational polity such as that offered by the EU. Here, 'reflexive Europeanisation' and thus the creation of a cultural-historical collectivity, or what we will call a European heritage demos, fails.

Nevertheless, we agree with commentators such as Sharon Macdonald (2013) and Gerard Delanty (2018) who argue, in different ways, that there is indeed a structural specificity within European heritage. This specificity is a result of historical developments, conditions and effects that have uniquely formed particular political orders, ways of life, value systems and memory practices. As Delanty argues, however, this is hardly homogenous across Europe, since modernity has been configured differently across the continent. We will return to these inspirations and the idea of European specificity in Chapter 2. Our general focus in this book, however, is on how heritage comes into being - is constructed - through representation. This is aligned with what Macdonald (2009, p. 118) has earlier termed an 'assemblage perspective' on heritage, directing 'our attention less to finished "heritage products" than to processes and entanglements involved in their coming into being and continuation'. This obviously means that the 'content' and meanings of heritage vary; its social purchase may be weak and irregular across different contexts. Once again, there can be multiple and competing ideas of European heritage, as actors call upon different pasts or connote them differently. Dialectically, these produce multiple Europes, made by different actors in different places, with different kinds of authority, agency and interests. (Since the idea of multiple Europes is not new, we shall return to it in Chapter 2.) Apprehending the tense, dynamic interaction of these Europes, their encounters, clashes and contrasts, may prove to be key to understanding the critical situation of the continent in the present.

\section{An 'Authorised' Heritage Discourse and alternate heritages of Europe}

Some of these ideas of European heritage are official ones. Together they constitute varieties of what Laurajane Smith has usefully termed an 'Authorised Heritage Discourse' (AHD), which draws some of its character from a European canon of heritage. AHD, in Smith's words, is 'based on the Western national and elite class experiences, and reinforcing ideas of innate cultural value tied to time depth, monumentality, expert knowledge and aesthetics' (2006, p. 299). It focuses on:

aesthetically pleasing material objects, sites, places and/or landscapes that current generations 'must' care for, protect and revere so that they may be passed on to nebulous future generations for their 'education', and to forge a sense of common identity based on the past. 


\section{Christopher Whitehead et al.}

Its authority lies in its own legitimising assumptions that it is universally applicable and that it is a commons that unites us. AHD thus relies on certain techniques and cultural practices: lists, canons, bureaucracy, the circulation of exclusive power to 'speak' among professionalised experts and a cultural elite, and the tendency to understand heritage as a 'boundaried' entity, as with a 'site', which is therefore easy to manage both at practical and psychological levels. One effect of the dominance of AHD is to impose a kind of lens through which, and only through which, people are able to view the past, limiting and reproducing the heritage canon and the connotations of the very idea of heritage.

If we accept that such a discourse is in fact in operation, we can also say that the EYCH 2018 excerpt cited at the beginning of this chapter actually represents an attempt at broadening the (AHD) canon; it actively tries to present other 'lenses' through which to understand heritage, including, as the reader may recall, the 'food we enjoy in company and the films we watch and recognise ourselves in'. It also seeks to evade a static view of heritage as something the people of the present must not change or compromise. And yet European heritage policy and discourse continues in many ways to operate as a modified 'authorised' discourse of this kind, for example in its assumptions regarding commonality and collectivity, identity building, transmission to future generations and 'universal value'. For example, in the quote above, the authors still evoke an ill-defined collective 'we' (consisting of 'Europeans', presumably) as its recipients.

Indeed, it can be argued that one of the strains to which European AHD is subject is its peculiar situation in between world orders. The AHD, as Smith notes, was forged as a cultural form in the nineteenth century in tandem with the development of nation-states. Its violence (or one of its violences) at the level of the national was to homogenise place discursively as nation, and thus to fail to attend to local distinctiveness or the multiple heritages and pasts that matter to people - including women and other non-dominant groups - outwith an elite invested in the national project. The nationally-framed AHD, with its emphasis on collectivisation and identity-making, was already, in this argument, insufficient to characterise the plethora of heritages in any given country. National AHD nevertheless forms a model for a European, and hence supra-national, AHD that is arguably even more ill-fitting, for this is of course an even larger territory to seek to make into a common ground; one in which ways of life, identities and historical experiences proliferate exponentially in comparison with those within a nation-state.

Another frame for collectivity is the United Nations concept of 'humanity' (originally 'mankind') and the connected notion of 'universal value' (sometimes 'outstanding universal value', a criterion for 'World Heritage' status). Since at least the 1972 UNESCO World Heritage Convention this concept has powered an ethics of global collectivisation that theoretically transcends national identities, though paradoxically it tends to reinforce them because nations are key administrative units within the proposal of what counts as 'world heritage'. European heritage sits uncomfortably in between these two national and universal frames. Neither national heritage writ large, abstracted to the scale of a 
continent, nor universal heritage writ small (for this would be oxymoronic), European AHD borrows tropes and techniques from each of these powerful scales. This adds considerably to the difficulties of defining European heritage, which begins to look less like a stock of actual stuff, and more like a political expression, a set of borrowings and contingencies, a leaky bureaucratic category through which to organise practice, but perhaps not to think on too closely, in case it should fail to hold.

Although we recognise AHD, as coined by Smith, as a useful analytical tool, in this book we adopt a broader understanding of heritage as a representational, discursive and performative practice involving conscious attempts to symbolically valorise aspects of the past in the present. Very often, such practice is conducted with a view to future-making. It can encompass 'discourse' in the sense used by Smith ('There is, really, no such thing as heritage' (2006, p. 11)) as well as the 'use of the past as a cultural, political, and economic resource for the present' (Ashworth, Graham and Tunbridge, 2007, pp. 2-3). It includes memory practice, where particular pasts are transformed into objects of ritual and performative remembrance and where historical symbols are called upon to express guiding values in the present. Representation is the common denominator, and here we can combine the different semantic possibilities of the term: representing, re-presenting, re-presenting.

We do not deny the reality of heritage insofar as it can be theorised nonsemantically and non-representationally: as pre-cognitive experience, as embodied presences, as inchoate affect and unconscious 'doing'. But such understandings are not our focus, and nor are they incompatible with an interest in the representational dimensions of heritage practice as a conscious mode of valorising the past in the present, and in expressing desires about the future. This can happen through, for example, the upholding, reviving or inventing of traditions; performative re-enactments and 'living history' practices; reconstructions (e.g. of buildings); policy papers and charters; conservation decisions and actions; commemorative practices; presentations of historical tangible and intangible culture; or imbuing and mobilising particular historical stories and phenomena with key significance for contemporary identities, for example in political speeches like Orbán's. In some cases, this involves a certain collapse - deliberate or unreflexive - of otherwise separate temporalities. Within the purview of this book, heritage can be official or unofficial, tangible or intangible, or mixtures of these. In some ways, we align our expansive approach with one of the key convictions of the Council of Europe's Framework Convention on the Value of Cultural Heritage for Society (Council of Europe, 2005a), known as the Faro Convention, which promotes the view that 'objects and places are not, in themselves, what is important about cultural heritage. They are important because of the meanings and uses that people attach to them and the values they represent.' $^{13}$

Indeed, there is hardly any particular entity that cannot qualify as heritage - at least for someone, as long as it is perceived as being of the past and of having symbolic value in the present. There is also no theoretical limit, or regulation on, 


\section{Christopher Whitehead et al.}

the meanings and uses ascribed to that past, nor on the nature of the values that people derive from them. Of course, we often find official attempts to police heritage, whether through legislation, policy or censorship, but this is not sufficient to pose theoretical limits on our definition. Particular attachments to 'heritage' as a symbolic valorisation of the past in the present need not be shared by large numbers of people and need not be ascribed 'progressive' or 'civil' meanings for them to have phenomenal social effect.

\section{BOX 1.2}

In 2011 the then-unknown Norwegian Anders Behring Breivik murdered 69 people on the island of Utøya, mostly youth members of the Norwegian Socialist Workers Youth League (Arbeidernes Ungdomsfylking, or AUF). He drew inspiration from a melange of historical symbols: the crusades, the Siege of Vienna of 1683 and Norse mythology (he inscribed the name of Odin's spear, Gungnir, in rune script onto his rifle). Through articulating and valorising such symbols, he also articulated a politico-historical vision of a European civilisation imperilled by otherness and multiculturalism. This extended into a project of murdering those - particularly the younger generation of AUF members - who welcome and celebrate difference within society. At this point, Breivik arguably became a kind of powerful heritage actor, irrespective of whatever distorted, selective, inaccurate version of the past he had fabricated in his imagination, or how morally unacceptable we might find his actions. This is, of course, an extreme case, but it shows that the serious effects of heritage are not entirely or solely in the control of elite jurisdiction, powerful 'authorised' discourses notwithstanding.

This concerns the tendency for actors to make alternate 'worlds' through recourse to the past. Personally-held attachments to heritage can be part of complex imaginaries in the sense articulated by Charles Taylor. That is, the way people 'imagine' their social existence, not in theoretical terms, but with 'images, stories, and legends': 'how [people] fit together with others, how things go on between them and their fellows, the expectations that are normally met, and the deeper normative notions and images that underlie these expectations' (Taylor, 2007, p. 23). Such imaginaries rely on and constitute a sense of self-inhistory, sometimes making for identity positions that are at odds with others, occasionally manifesting in large-scale social and political division with momentous consequences. Such imaginaries do not replace AHD, but frequently clash with it.

Similarly, we diverge from a 'pure' AHD expression of who the actors and what the objects of heritage are. In instruments such as the Faro Convention, or UNESCO's more recent iterations of the World Heritage Convention's Operational Guidelines, ${ }^{14}$ there is an ethical drive to incorporate 'community' perspectives on heritage, leading to technical developments such as co-production models that enable this. This is an important and welcome shift (although not 
without its problems and paradoxes), but we are more concerned here to reflect upon the everyday circulation and importance of heritage in people's lives at the level of banal and mundane concerns as well as political convictions. People are, in some ways, heritage actors irrespective of official attempts to enable this, and while they do not tend to benefit from 'authorised' status nor count as the expert figures responsible for producing and upholding the AHD, they may certainly wield power within the physical, digital, social and public spaces of their own lives. Heritage is not contained by a list or set of sites, objects and practices. Rather, it circulates continuously - and often somewhat uncontrollably - through private and public space, experience, imagination and discourse, at different scales, and in dynamic relations with contemporary social, economic, cultural and geopolitics.

\section{Dimensions of heritage}

Once we examine how heritage is constructed, we may look in turn at what 'heritage', as discourse and practice, itself produces, or is used to produce. This is to talk of its discursive effects that may be imbricated within profoundly significant socio-political change, or within the lifeworlds of individuals as a reference for making sense of the present and, reflexively, of themselves. Heritage 'happens' in different ways and spaces, through different forms of iteration. Each of these is capable of producing particular effects. In this book, we term these modalities and spaces of heritage dimensions, as we will explain in depth below. Our contention is that through such different dimensions in which heritage figures, certain realities are made, or made possible. More specifically, in our chosen settings, certain 'Europes' are produced that are necessarily discursive constructs, but that very often - indeed usually - have structuring effects. For example, we will see shortly that the 'dimension' of heritage policy-making constructs a particular idea of Europe, comprising its history, peoples, political orientations and social and moral values. It does so through particular rhetorics and techniques that actively structure 'outcomes', most obviously through authoritative and top-down forms of funding (see Chapter 3, this volume). As we saw in the EYCH discussion earlier, the Europe that is evoked through this dimension of policy is never merely conceptual or discursive, and never just an idea, for it precipitates action that may strongly configure social, political and physical space.

'Dimension' is a term often cursorily used in the academic vernacular, but we aim to use it as a figure with precise, if multiple, meanings. In its Latin etymology, 'dimension' concerns measuring, dimetri - to measure out - which for us holds a range of helpful connotations, linking to the way actors try to map and chart Europe and its history, or to how the EU seeks to measure European heritage through its lists, prizes, definitions and data gathering. In a governmental sense, measurement is about controlling expressions and meanings, and being able to demonstrate and quantify effects. More recently, it has taken on other meanings whereby one's citizenship, or right to citizenship, can be measured, as 
in points-based assessments for prospective immigrants. It is also about identifying the scale and coverage of things - 'Europe' in this case - and, therefore, establishing boundaries and borders of containment and limitation. These boundaries and borders may be literal, with obvious real-world effects concerning the control of peoples and bodies - as in the case of the Serbian-Hungarian border fence (see Chapter 9, this volume) - and/or they may be abstractions, like when actors talk about what counts or does not count as European heritage, or as a European value. Here, indeed, acts of mental measuring, parsing and bordering are undertaken, whose effects at different scales, from the geopolitical to the individual lifeworld, may be no less profound for inclusion and exclusion than a securitised metal fence. Scalings of Europe are part of the 'work' of dimensions, and dimensions are also capable of transecting different scales. Consider, for example, one of the dimensions of heritage that we examine in this book, which we call 'reversions'. This is about nostalgic and commemorative returns to a particular past, whether through re-enactment, reconstruction and rebuilding processes or revivals. A case in point is the popular annual D-Day Festival in Normandy, where amateur enthusiasts show off their lovingly maintained military vehicles to crowds eager to celebrate the uncomplicated moral heroism of the Allied liberators of Nazi-occupied France and Europe in 1944. The enthusiasts and crowds alike are part of a multi-scalar assemblage in which powerful politicians are also present as memory actors. International relations occur, and the world order is formed at the high scale, for the negotiation of contemporary geopolitical relations is made in reference to a symbolic past. The dimension of reversion 'scales' a particular Europe in relation to the past, but it also crosses through multiple scales, in each of which the past is called upon (recalled) to make futures.

In a second understanding of 'dimensions' we turn to its sci-fi connotations. Many of us have grown up with books and films offering the tantalising possibility of alternate realities. This is the idea that in some other dimension things could be subtly or radically different. To entertain this is to make a cut into the ordinary surfaces of human experience, through which one might glimpse worlds that are both alien yet uncannily familiar. Through this insight, we might be motivated to look again at ourselves and our situations and perceptions. This is what gives the idea of 'dimensions' power as a device of fiction. It alters our perception by showing us other worlds and ways of thinking, being and perceiving. Alternative imaginaries are made possible that in turn may lead us to rethink ourselves and our positions in time, place and society.

For the purposes of writing this book, this sci-fi inspiration allowed us to think not of one Europe but of several possible or competing Europes. We do not have to turn to make-believe, or to theoretical physics and cosmology, to propose this. The Europe produced by European Council (EC) directives and heritage policies may be quite different from that produced by the German farright collective PEGIDA (Patriotic Europeans Against the Islamisation of the Occident). It may have different coverage, emphases, politics, values and affects; and even that is to assume, simplistically, that only one Europe is produced respectively by the EC or PEGIDA. In the case of the EC, this is a dimension of 
supranational, authoritative, instrumental and electorally-mandated policymaking, capable of distributing significant financial and symbolic capital. In the case of PEGIDA, we may understand its operations as occurring within a dimension of perceived loss, expressed in mass gatherings and other performances and representations of protest. These and many other Europes may spread and circulate differently and follow their own trajectories. They may also, of course, occasionally come into contact, informing, ignoring or reacting against one another in a multi-dimensional interplay that possesses no particular overall harmony and certainly no overall co-ordination or plan. Addressing European heritage through such a lens allows us to consider how heritage is produced through multiple actors, techniques and agendas, from local hobby groups of historical reenactors to officially listed world heritage sites, or how there come to be distinctive understandings of what European identity and heritage is - whether secular, Christian or multi-faith, aristocratic or industrial, northern or southern, national or transnational, and so on - bearing in mind that these too are often in themselves heterogeneous and contested concepts.

The dimensions of European heritage upon which we focus in this book are only homogenous insofar as they are technical and affective spaces. These are



Figure 1.3 At the Victoria and Albert Museum's Europe 1600-1815 galleries, this space sits within the Enlightenment; it is intended as a discussion space, a museal translation of a salon where dialogues about the meanings of 'European' art are held. 
metaphorical (but sometimes also geographically situated) spaces in which certain techniques are available and certain emotional appeals are made possible. Through such techniques and appeals, collectivities are discursively constructed that refer to geohistorical imaginaries and construct a self-in-history. Through collectivisation, senses of belonging resonate within relational constructions of place, time and people. The dimensions we choose to focus on are: policy, insofar as it defines, creates and instumentalises a 'European heritage'; the nation, as a frame of belonging through which actors articulate resistance, and/or relations, to a wider frame of 'Europe', and through which other pasts are evaded, such as colonial ones; reversions and reprisals, which call upon mobilisations of particular pasts for world-making in the present; difficult history as a formative narrative for European identities; loss as an affective dimension that enables or compels actors to fashion particular subject positions and requires particular kinds of memory work; and edges as a situated positioning, where we ask what kind of 'Europe' is visible from the peripheries, whether these are taken to refer to geographical, compass-point extremes or locales at the brink of social and economic rifts.

In each of these dimensions, opportunities vary for forms of representation, for performance, for making use of media and for audience and seeking purchase, as do the levels of agency of actors. The Europe created in a dinner-table discussion cannot 'behave' in the same way as one made through a right-wing interest website, or one produced in a piece of EC policy. And yet it is their coexistence and often tense interaction that makes Europe and European heritage both multiple and fluid. Acknowledging this fluidity, we contend that notwithstanding their differences, these dimensions of European heritage are comparably affected by certain forces of motion, or dynamics, while also contributing to their further development, travel and effects. For example, and as already discussed, a crisis dynamics (or a sense of it) will be felt in different ways across different dimensions, triggering different effects and affects. It will be felt, and it may change things, in the boardroom and at the dinner table, in the street protest and in top-down heritage funding streams. Similarly, dynamics are variously created through the encounters between peoples, groups belief systems, materials and technologies, that have different effects and affects in the dimensions we study, sometimes leading to social contests about what is true and right. For example, the crossing of refugees into Europe is presently a key dynamic that has led to different iterations of Europe and European heritage, including both cosmopolitan and xenophobic, and inclusive and exclusive, views of what Europe is, and how that relates to its past and future.

In short, dimensions are spaces wherein certain techniques, whether bureaucratic, rhetorical or governmental, and affects make scripts for collectivisation, for a 'self-in-history' and for a future world that is in some way better than the present - whether we are talking about the policy aim of fostering greater intercultural understanding and civility or someone's nostalgic desire to return to the old ways and the old days, 'before things went wrong'. Dimensions are a binding-together of technical, affective and political matter to produce worlds. 
They come more strongly 'into play' according to political and emotional contingencies and, though they can be invoked tactically for political effect, they can 'go on' in their effects, with some autonomy, not least because they intersect and their effects multiply and promulgate (cf. Macdonald 2013: p. 4). There are of course other possible dimensions that we have not explored, in some cases because they have had relatively full treatment elsewhere, such as what we might call the affective dimension of 'regret' (Olick 2007). The attentive reader may also notice overlap between these dimensions, and this is a product neither of intellectual laxity nor coincidence; rather, it is an imprint of the relational and dynamic behaviour, interaction and intertextuality of dimensions in which worlds - and selves - are made from the past.

\section{The structure of this book}

This chapter has outlined the origin of this book, as a product of EU-funded research into the potentials to identify and constructively mobilise 'the' European heritage for social, political and collective benefit, involving the making of a 'European heritage demos'. We have explained how we have spoken back to this agenda, tilting the frame, as it were, to propose an alternative, realist perspective that there is hardly one monolithic European heritage, and therefore, discursively and effectively, no single Europe. This multiplication of meanings is produced through an array of dimensions that are much more numerous and pervasive than conventional bracketings of where heritage 'sits' within public, cultural and social life. This makes 'European heritage' difficult to contain, to regulate and to measure out in the ideal form desired by policy-makers; it may even mean that the heritage demos is a dream that cannot be realised. In our conclusion to this book we return to these problems with some constructive suggestions.

Chapter 2, Remapping European heritage and memory, provides a mapping of the overlapping fields with which this book is concerned, in order to set out some working positions on heritage and its uses that enable constructive connections with the fields and theories that relate to it, while also articulating relations to practice and to instrumental agendas. Can memory have a collective dimension, and how is this manifest in constructions of European memory? What then are its articulations with history, heritage and identity? This chapter presents some of the prickly definitional questions encountered throughout the volume ('heritage', 'memory', 'history', 'Europe' etc.) and axiological issues concerning the social and civil purpose of the research. It offers an integrated account of heritage and memory cultures in Europe that engages not just with scholarship, but also takes policy, regulation and practice seriously, as means through which heritage, memory and identity are theorised.

These problems point to methodological concerns: how do we make sense of a dynamic, fluid, opaque entity such as Europe, particularly in relation to equally complex and vague notions such as heritage and memory? The idea of covering all geographical territory evenly would lead to superficial and historically unspecific 
understandings, and - of course - Europe has changed and is changing, as borders, countries and meanings are defined, redefined and often contested. Europe is also not understandable in isolation - as Gerard Delanty argues, in an important regard Europe is fundamentally 'non-European', because its historical development is so obviously not limited to endogenous factors. As discussed, ideas of heritage and memory are also mutable and matters of dissent, not just in 'authorised' contexts and definitions produced by official institutions (e.g. UNESCO, the EC, national governments, etc.) but also by different social groups and in scholarship. So then we are faced with a set of particular problems that are not just methodological but also conceptual and political: if we are to get at 'European heritages', when both the individual components of this term and their combined meanings are so disputed, then what is it that we should study, and how? Any articulation of method in such a context has profoundly political liabilities and we discuss our approaches and positions - including ethical ones - to this issue.

The following chapters work through a number of key areas, in which we observe the operation and interplay of certain dimensions of the production of heritage and memory. In Chapter 3, The instruments of European heritage, Zito et al. argue that if we are to consider the dimensions of European heritage and memory it is imperative to examine the official - the dimension of the legal and political instruments and policies that seek to preserve, record, interpret, transmit and also to create an official European heritage and a European backstory. The chapter focuses in particular on two formal European political arenas that are creating European heritage and narratives, namely the Council of Europe (COE) and the EU. The chapter shows the plethora of political instruments and policies that both political organisations have produced that relate to or have a bearing on heritage practice, sometimes incidentally and sometimes more purposively and explicitly. The landscape of these instruments is confusing to navigate. Furthermore, there are often deep underlying tensions that lurk beneath these efforts, including for example the focus on embracing unity through diversity. How then do policy-making institutions seek to intervene and make people engage with memories, histories and identities by creating cultural heritage institutions and instruments? After a discussion of the different ways in which heritage instruments promote European integration in the Council of Europe and the European Union, the chapter narrows the focus onto two examples: the European Heritage Label (EU) and the European Landscape Convention (COE), opening perspectives onto the policy construction of Europe and its heritage.

In Chapter 4, Reversion and reprisal, Daugbjerg et al. explore practices that seek to remake the past in the present, whether in architectural and landscape form, as in open-air museums, or rebuilding projects, and in re-enactments and immersive environments such as panoramas. These sometimes relate to topdown appeals to citizens to cultivate attachments to particular pasts and to model a sense of self-in-history that is auxiliary to political identities. In less overtly governmental settings, people who feel embattled or alienated by social change may use heritage to exercise a desire to revert to imagined cultural worlds. 'Reversions' is a way of thinking about the process of looking to the past to find 
alternative futures that put back in place what has been lost, while its secondary meaning - making successive versions - speaks to creative and plural imaginings of the past.

In Chapter 5, Edges and centres, Whitehead et al. explore the margins. They argue that from the edges we see things differently and a boundary (perceived or otherwise) is a particular vantage point in which subjects are positioned, or position themselves. 'Edge' places often have particular geohistories that are made as a result of their peculiar location and the spatial politics they are embroiled in, often because of their strategic value for conferring control of space and symbolic dominance (e.g. the Dardanelles). Edge places attract certain kinds of event because of their geopolitical position. This then leads to 'edgy heritage' in which crossings, crises and contests are deeply and peculiarly felt. They are conceptual as well as literal borderlands, for they are spaces of oscillation, contamination and negotiation between cultures and heritages. Edges may be seen as the measured and charted limits of identity or the extreme points at which the extent of something (Europe) terminates, as spaces of containment, ingress to and exit from the scene. They may seem to be marginal spaces that matter less, but they can take on high salience: as places that mark a tactical non-plus-ultra, as places that may be lost, forcing a rebalancing of Europe (e.g. the uncertain fate of the island of Ireland as one of the western edges of Europe); as contested places, bridges to, transitional spaces or forcefields between, other worlds (Turkey, Andalusia, Scandinavia, Ireland). But the 'edges' of Europe are not just geographical - they can also be socio-economic, political, moral or ethnic: compasses of different sorts. The chapter argues that edge places of different kinds offer a peculiar spatial and affective dimension in which both to view, make and unmake different Europes, where symbolic imaginaries and geopolitics come into relation.

In Chapter 6, Situating belonging at the intersection of multi-scalar, multidimensional and multidirectional heritage, Markham et al. focus on a site that is both centre and edge. The historic port city of Gdańsk in Poland is - in some narratives - tightly central to a European story of trade, industry and emancipation from oppression by way of the Solidarity Movement. The city itself is a recipient of conspicuous EU funding through which - together with private investment - considerable heritage and gentrification projects are afoot. Against this frame, the authors explore the conundrum of people's apparent lack of sense of allegiance to European-level bodies such as the EU, even as they live in places structurally shaped by that same body, and even as they may still identify as having a stake in a more general concept of European history. They draw on Eriksen's concept of a 'clash of scales' to explain the mismatches and tensions between different mobilisations of the past, in which contrasting affective repertoires and subject positions are evident as part of the tense making of place.

In Chapter 7, on the paradoxes of time, place and memory, Eckersley and Bozoğlu analyse 'difficult' heritage in connection with the paradox of democracy and Arendt's 'promise'. 'Difficult history', the chapter argues, exists in a shifting spatio-temporal dimension, beset by paradoxes which circulate and 
recirculate challenges from the past, present and future. As the touchstone of the EU's story, Eckersley and Bozoğlu analyse: how the Holocaust is put to service as a paradoxically universal and singular 'negative founding myth' which has persisted over time; the ways in which simultaneously shared yet divided European memories pertain to contemporary political tensions; and the impact of absent memories and contested belonging within the European heritage record. The authors examine these in multiple museum and memorial heritage site representations, including the House of the Wannsee Conference, Auschwitz Memorial and Museum, Schloss Cecilienhof - the site of the Potsdam Conference, the Museum of the Second World War in Gdańsk, and the Lepsiushaus in Potsdam. A spatial and digital 'site': the Houshamadyan web Archive, which constitutes a vast, digital recuperation or rescue of lost Ottoman-Armenian memory, provides an 'unofficial' memory book for Europe, in contrast to the 'official' heritage sites. Bound up and entangled with Arendt's 'promise' and the paradox of democracy - past, present and future time is found here to be in flux, through the 'continual unsettlement' (Macdonald 2009) of European memory by different actors within the politics and practice of heritage.

In Chapter 8, On the politics of selective memory in Europe, Gurminder K. Bhambra questions one of the principal 'founding myths' of the European Union, which is that it is an assembly of nations seeking to avoid the recurrence of war through a brand of cosmopolitanism that balances national difference with European commonality. This, in her argument, is a selective remembering, or a kind of tacit, discursive trick, to evade engagement with the different backstory of European colonial endeavour. This means that the 'diversity' of EU member states is misrecognised, the historical nature of those states as colonisers goes unacknowledged, and their multicultural societies are seen as an imposition of the recent past and present (a cause of crisis), rather than as foundational and fundamental constituents of Europe.

In our thinking, the 'nation' as frame constitutes a dimension - a technical and affective space - through which a 'Europe' is constituted as an imaginary in which member states have "purified their histories as national histories and imagined their political communities as composed of "kith and kin", . This is to say that the member state as nation is a dimension of othering, disentitlement and disinheritance, in the sense articulated by Tunbridge and Ashworth (1996, p. 21), wherein a 'European' heritage is possessed by 'Europeans' and is therefore logically not the proper possession of 'others'. To be sure, there is an extensive debate in museology and museum practice about the role of former colonial ethnographic museums, maritime and city museums in recognising colonial pasts and admitting historical culpability, more or less according to a 'difficult history' paradigm. One can, however, doubt the extent to which heritage initiatives actually stitch colonialism into a story of state formation, and into a politics of the European present. Such disjunction allows powerful actors to claim that multiculturalism has 'failed' as if it were some kind of graft that has failed to take onto the pre-formed body of the state. If, as this chapter argues, there is a kind of wilful misremembering of European history, what other 'Europe' would emerge 
from an alternative view? What 'European heritage' could be identified and to whom could that belong?

In Chapter 9 the editors are joined by filmmaker Ian McDonald, in a reflection on the specially-commissioned film Who is Europe? The film is a creative analogue to this book, although we hope it has productively contaminated our writing and editing too. It was made at the same time, for the same project and in response to common theoretical and political underpinnings. The film documents different sites and subject positions from those exemplified in this book, but with a comparable attention to the unexpected and unintended dimensions and heritage through which Europe is made. Like many of the contributions to this book, it works through locations, observations, dissonances and contrasts. The dominant structural formal devices of the consecutive 'acts' and the split-screen format present the plurality, dialectics and friction between worlds, between imaginaries and subject positions. We introduced the figure of the split-screen earlier, in relation to Orbán's politics of exclusion and the European Year of Cultural Heritage's celebratory, collectivising discourse. It is fitting that the film returns to these very grounds (among others), exploring both the new Hungarian border fence and a Europe-wide orchestration of bell-ringing to celebrate peace. Above all, the film asks the critical question expressed in its title - a question that recurs throughout all of the contributions to this book - who is Europe? From here, other interrogatives automatically converge: what, where, when, how, why, whose?

In Chapter 10, the editors bring together the different strands of the book to propose some final thoughts concerning the role of heritage and memory in the production of different collectivities and forms of belonging that co-exist and clash. This is to say that the European 'heritage demos' can only ever fail as a project of total collectivisation, and indeed has the inherent liability to function as an object against which alternative collectivities are organised reactively and antagonistically.

Other forms of collectivisation, such as the promotion of national identities or value-driven moral and cosmopolitan communities (Guibernau, 2007; Lister and Pia, 2008) have also been implicated in considerable social and political divisions, including the rise of xenophobic and atavistic nationalism and the vilification of 'citizens of nowhere' (as Theresa May famously termed those who would claim a post-national identity as 'citizens of the world' in 2016). What, if anything, can heritage offer as a frame or container for collectivisation? Chapters in this book show that collectivisation in reference to the symbolic valorisation of the past is hardly a good in itself: memory communities often collectivise around atavistic and exclusionary heritages in order to negotiate a shared self-in-history that may be an anxious or aggressive response to change, alienation and loss of control. Here we return to the constant tensions between homogeneity and heterogeneity that beset rhetorical and policy constructions of unity in diversity. We explore this in some depth through the use of interviews and focus groups conducted at heritage sites of different sorts which problematise what we call the European heritage 'record' (as a kind of political analogue to the fossil record) and its relations to belonging or nonbelonging. What should heritage actors do in pursuit of community and civility? 
We argue that the potential exists for heritage initiatives and museums to work creatively to bring historical narratives to bear on today's concerns and ask questions about relationships between past and present, in order to encourage reflexive and critical understandings of our self - or selves - in history.

\section{Notes}

1 This chapter is available open access as part of the European Union-funded Horizon 2020 research project: CoHERE (Critical Heritages: performing and representing identities in Europe). CoHERE received funding from the European Union's Horizon 2020 research and innovation programme under grant agreement no. 693289.

2 Grant number 693289; https://cordis.europa.eu/project/rcn/199996/factsheet/en

3 https://researchbriefings.parliament.uk/ResearchBriefing/Summary/CBP-8060\%23 fullreport

4 https://cordis.europa.eu/programme/ren/664966/en

5 www.theguardian.com/commentisfree/2016/oct/31/refugees-problem-europe-identitycrisis-migration

6 European Museums in an Age of Migrations (MeLa), 2011-15, EU FP Grant Agreement 266757. https://cordis.europa.eu/project/rcn/99606/factsheet/en.

7 E.g. www.huffingtonpost.co.uk/jacob-furedi/eu-referendum-brexit_b_10543692.html; also in relation to ECHR: www.ukipdaily.com/magna-carta-europe-now/

$8 \mathrm{https} / /$ europa.eu/cultural-heritage/about_en

9 www.kormany.hu/en/the-prime-minister/the-prime-minister-s-speeches/prime-ministerviktor-orban-s-address-in-parliament-before-the-start-of-daily-business20160912

10 'European-level' is intended here to comprise policy initiatives of multiple kinds and from different bodies, including the European Commission, European Parliament, Council of Europe as well as sectoral actors such as Europa Nostra, Culture Action Europe etc., that address and seek to frame notions of the value of heritage in and for 'Europe' as a trans- and/or supranational entity. For a survey and classification of policy see Chapter 3, this volume. Recent initiatives that rely on the notion and valorisation of a shared European heritage include, among others: Conclusions on Cultural Heritage as a Strategic Resource for a Sustainable Europe (Council of the European Union, 2014); Communication Towards an Integrated Approach to Cultural Heritage for Europe (European Commission, 2014); Getting Cultural Heritage to Work for Europe (European Commission, 2015); Cultural Heritage Counts for Europe (ChCfe, 2015); Political Statement on the Occasion of the 60th Anniversary of the Rome Treaties: Culture at the Heart of a Sustainable Europe (European Alliance for Culture and the Arts, 2017); Strategy 21: European Heritage Strategy for the 21st Century (Council of Europe, 2017); A New European Agenda for Culture (European Commission, 2018); The Berlin Call to Action: Cultural Heritage for the Future of Europe (Europa Nostra, 2018).

11 See for example www.miniszterelnok.hu/orban-viktor-beszede-a-felujitott-hagyomanyokhaza-atadojan/

12 www.consilium.europa.eu/uedocs/cms_data/docs/pressdata/en/educ/142705.pdf

13 www.coe.int/en/web/culture-and-heritage/faro-convention

14 https://whc.unesco.org/en/guidelines/

\section{References}

Ashworth, G.J., Graham, B. and Tunbridge, J.E. (2007) Pluralising Pasts: Heritage, Identity and Place in Multicultural Societies. London: Pluto Press.

Delanty, G. (2018) The European Heritage: A Critical Re-interpretation. London: Routledge. 
Eder, K. (2014) 'The EU in Search of its People: The Birth of a Society out of the Crisis of Europe', European Journal of Social Theory, 17(3), pp. 219-237.

Eriksen, T.H. (2016) Overheating: An Anthropology of Accelerated Change. London: Pluto Press.

EU Directorate-General for Research and Innovation (2015) Getting Cultural Heritage to Work for Europe. Brussels: European Commission. Available at: https:/ec.europa.eu/ programmes/horizon2020/en/news/getting-cultural-heritage-work-europe (Accessed: 28 January 2019).

European Union (2018) '2018 European Year of Cultural Heritage' https:/europa.eu/ cultural-heritage/european-year-cultural-heritage_en

Guibernau, M. (2013) Belonging: Solidarity and Division in Modern Societies. Cambridge: Polity.

Guibernau, M. (2007) The Identity of Nations. Cambridge: Polity.

Handler, R. (1985) 'On Having a Culture: Nationalism and the Preservation of Quebec's Patrimoine', in Stocking, G.W. (ed.) Objects and Others: Essays on Museums and Material Culture. Madison, Wis.: University of Wisconsin Press, pp. 192-217.

Koselleck, R. (2006) 'Crisis', Journal of the History of Ideas, 67(2), pp. 357-400.

Krasnai, Z. (2017) 'Cultural Heritage Topics in the Upcoming 2018-2020 H2020 Work Programme and European Year of Cultural Heritage 2018', CoHERE-TRACES Joint Conference Critical Heritages and Reflexive Europeanisation, Berlin Wall Memorial Visitor Center, 28 September 2017.

Lähdesmäki, T. (2018) 'Founding Myths of European Union Europe and the Workings of Power in the European Union Heritage and History Initiatives', European Journal of Cultural Studies, pp. 1-18.

Leggewie, C. (2010) 'Seven Circles of European Memory', Eurozine, available at: www. eurozine.com/seven-circles-of-european-memory/ (Accessed: 28 January 2019).

Lister, M. and Pia, E. (2008) Citizenship in Contemporary Europe. Edinburgh: Edinburgh University Press.

Macdonald, S. (2013) Memorylands: Heritage and Identity in Europe Today. London: Routledge.

Macdonald, S. (2009) 'Reassembling Nuremberg, Reassembling Heritage', Journal of Cultural Economy, 2(1-2), pp. 117-134.

Olick, J.K. (2007) The Politics of Regret: On Collective Memory and Historical Responsibility. Abingdon: Routledge.

Pomian, K. (2009) 'European Identity: Historical Fact and Political Problem', Eurozine, available at: www.eurozine.com/european-identity-historical-fact-and-political-problem/ (Accessed: 28 January 2019).

Taylor, C. (2007) A Secular Age. Cambridge, Mass.: Harvard University Press.

Tunbridge, J.E. and Ashworth, J.G. (1996) Dissonant Heritage: The Management of the Past as a Resource in Conflict. Chichester: Wiley.

Smith, L. (2006) Uses of Heritage. London: Routledge. 